\title{
Bases para uma política nacional de ciência, tecnologia e inovação em saúde
}

\author{
The basis for a Brazilian national policy in science, \\ technology, and innovation in health
}

\footnotetext{
1 Departamento de Ciência e Tecnologia do Ministério da Saúde e Conselho Superior da Faperj.

Esplanada dos Ministérios Bloco G, Ed Sede 8o andar. 70058-900 Brasília DF. rfg@saude.gov.br>
}

\begin{abstract}
This paper discusses the basis for a Brazilian National Policy in Science, Technology, and Innovation in Health (PNCTI/S) as the structural element for a Brazilian health research effort. At least since the National Research Council (CNPq) was founded in 1951, this huge effort, including a set of nearly 18,000 researchers in 4,900 research groups, has not been backed by an explicit national health research policy. The paper takes the view that the appropriate body for establishing this policy is the Ministry of Health, as occurs in the majority of countries with a research tradition. Such a National Policy should be backed by a priority research agenda, developed through agreement by the most relevant players, namely health researchers and managers. The National Policy should be extensive in relation to the knowledge chain and inclusive towards researchers and research institutions. Finally, it should be based on the quest for equity in health and ethical research standards in practice.
\end{abstract}

Key words Science and technology, Health research, Strategic research
Resumo O texto discute as bases para uma Politica Nacional de Ciência, Tecnologia e Inovação em Saúde (PNCTI/S) como elemento estruturador do esforço brasileiro de pesquisa em saúde. Pelo menos desde a fundação do CNPq, em 1951, esse imenso esforço, que no Brasil se traduz por um conjunto de quase 18.000 pesquisadores atuantes em 4.900 grupos de pesquisa, não se sustenta em uma política pública explícita de pesquisa em saúde. O texto adota o ponto de vista de que o organismo adequado para constituir essa política é o Ministério da Saúde, de resto como ocorre na maioria dos países com tradição em pesquisa. Uma PNCTI/S necessita ser respaldada em uma agenda de pesquisa prioritária, cuja construção deve ser pactuada entre os atores mais relevantes, quais sejam os pesquisadores e os gestores de saúde. Deve também prever novos canais e fontes de fomento. A PNCTI/S deve ser extensiva no que se refere à cadeia do conhecimento e inclusiva no que toca aos pesquisadores e instituições de pesquisa. Por fim, deve sustentar-se na busca da eqüidade em saúde e na prática de padrões éticos de pesquisa.

Palavras-chave Ciência e tecnologia, Pesquisa em saúde, Pesquisa estratégica 
À memória de Sérgio Arouca, sanitarista brasileiro $(1941-2003)$

\section{Introdução: a importância da pesquisa em saúde}

Com a possível exceção da pesquisa militar, a saúde é o setor que despende a maior quantidade de recursos em termos mundiais. Em 1998, segundo o Global Forum for Health Research, estimava-se terem sido algo como US\$ 73,5 bilhões, mais de $90 \%$ nos países ricos e visando resolver os problemas dos países ricos. $\mathrm{E}$ no Brasil, qual a relevância da pesquisa em saúde? Em primeiro lugar, cabe uma delimitação. Por motivos variados, a pesquisa em saúde costuma ser circunscrita, mesmo em alguns ambientes especializados, ao seu maior, mas de modo algum exclusivo, componente: a pesquisa biomédica. Essa imprecisão conceitual gerou uma complicação metodológica e uma acomodação empírica. A complicação foi a de considerar "saúde" uma área do conhecimento, quando se trata de um setor de aplicação ou de atividade. A acomodação empírica subseqüente foi medir o esforço de pesquisa em saúde pelo somatório daquilo que na árvore do conhecimento do CNPq está incluído nas grandes áreas das ciências da saúde e das ciências biológicas.

Numa perspectiva conceitual expandida e numa abordagem setorial, cerca de $50 \%$ do esforço de pesquisa em saúde no país provém de grupos vinculados às ciências da saúde, cerca de $25 \%$ provêm de grupos vinculados às ciên- cias biológicas e os $25 \%$ restantes de grupos das demais grandes áreas. Essa repartição é exclusivamente quantitativa. Os $25 \%$ das ciências biológicas se referem quase que exclusivamente a grupos pertencentes às áreas cobertas pela $\mathrm{Fe}$ deração das Sociedades de Biologia Experimental (FeSBE), à genética e à microbiologia/parasitologia. Dentre as demais grandes áreas do conhecimento, as ciências agrárias, as ciências humanas e as ciências sociais aplicadas possuem uma presença maior. As engenharias e as ciências exatas e da Terra estão presentes em grau bastante pequeno. Esse desenho mobiliza, nos dias de hoje, cerca de 4.900 grupos, com 18.000 pesquisadores (11.000 doutores) e circunscreve cerca de $30 \%$ do esforço global de pesquisa no Brasil (CNPq, 2002). Trata-se do maior componente científico-tecnológico apropriável num único setor ou grande área do conhecimento no país. Números de contorno da pesquisa em saúde no Brasil para 2002 estão nas tabelas 1 e 2.

\section{A “reemergência" da pesquisa em saúde}

No plano histórico, a importância da pesquisa em saúde no Brasil é largamente reconhecida, estando os institutos de pesquisa em saúde dentre os primeiros e mais importantes do país desde o século 19, na tradição de Claude Bernard, de Pasteur e da escola alemã. Da mesma forma, naquela que poderíamos denominar de fase acadêmica da pesquisa brasileira (a partir de 1934, com a fundação da Universidade de São Paulo), a pesquisa em saúde sempre ocu-

\section{Tabela 1}

Grupos que atuam em saúde e total de grupos cadastrados no Censo 2002 do Diretório dos Grupos de Pesquisa, segundo a grande área do conhecimento predominante nas atividades dos grupos.

\begin{tabular}{lccc}
\hline Grande área do conhecimento & $\begin{array}{c}\text { Grupos que atuam } \\
\text { em saúde }\end{array}$ & $\begin{array}{c}\text { Total de grupos } \\
\text { cadastrados }(\mathbf{T})\end{array}$ & $\begin{array}{c}\% \\
(\mathbf{S}) /(\mathbf{T})\end{array}$ \\
\hline Ciências da Saúde & 2.507 & 2.513 & 99,8 \\
Ciências Biológicas & 1.129 & 2.126 & 53,1 \\
Ciências Humanas & 430 & 2.399 & 17,9 \\
Ciências Exatas e da Terra & 319 & 2.051 & 15,6 \\
Ciências Agrárias & 216 & 1.653 & 13,1 \\
Engenharias e C. da Computação & 199 & 2.243 & 8,9 \\
Ciências Sociais Aplicadas & 91 & 1.429 & 6,4 \\
Lingüística, Letras e Artes & 23 & 744 & 3,1 \\
Total & 4.914 & 15.158 & 32,34 \\
\hline
\end{tabular}

1 Grande área do conhecimento predominante nas atividades dos grupos de pesquisa.

2 Grupos com pelo menos uma linha de pesquisa relacionada à grande área Ciências da Saúde ou ao setor de atividade Saúde Humana. 
Tabela 2

Número de grupos, linhas de pesquisa e pesquisadores que atuam em saúde, segundo a grande área do conhecimento predominante nas atividades dos grupos.

\begin{tabular}{|c|c|c|c|c|c|c|}
\hline $\begin{array}{l}\text { Grande área do } \\
\text { conhecimento }\end{array}$ & Grupos & $\begin{array}{l}\text { Linhas de } \\
\text { Pesquisa }\end{array}$ & $\begin{array}{l}\text { Pesquisa- } \\
\text { dores }\end{array}$ & Doutores & $\begin{array}{l}\text { Pesquisa- } \\
\text { dores }\left(\mathbf{P}^{\star}\right)\end{array}$ & $\begin{array}{l}\text { Doutores } \\
\qquad\left(D^{*}\right)\end{array}$ \\
\hline Ciências da Saúde & 2.507 & 7.958 & 13.371 & 8.277 & 10.302 & 5.886 \\
\hline Ciências Biológicas & 1.129 & 3.261 & 5.054 & 4.064 & 3.983 & 3.081 \\
\hline Ciências Humanas & 430 & 864 & 2.003 & 1.113 & 1.825 & 979 \\
\hline Ciências Exatas e da Terra & 319 & 544 & 1.210 & 957 & 1.142 & 896 \\
\hline Ciências Agrárias & 216 & 479 & 1.025 & 710 & 725 & 463 \\
\hline Engenharias e C. da Computação & 199 & 410 & 782 & 596 & 727 & 547 \\
\hline Ciências Sociais Aplicadas & 91 & 131 & 352 & 175 & 339 & 165 \\
\hline Lingüística, Letras e Artes & 23 & 41 & 110 & 58 & 108 & 56 \\
\hline Total & 4.914 & 13.688 & 23.907 & 15.950 & 19.151 & 12.073 \\
\hline $\begin{array}{l}\text { Todas as grandes áreas sem } \\
\text { dupla contagem de pesquisadores }\end{array}$ & & & & & 17.773 & 10.938 \\
\hline
\end{tabular}

$\left(\mathrm{P}^{\star}\right)$ Pesquisadores sem dupla contagem.

$\left(D^{*}\right)$ Doutores sem dupla contagem.

pou um lugar de destaque, na qual permaneceu durante o período inaugurado com a criação do CNPq em 1951. No entanto, entre aquelas duas primeiras fases e esta última operou-se um crescente divórcio entre o núcleo hegemônico da pesquisa em saúde e as políticas de saúde, que se traduziu em um afastamento crescente entre a temática da pesquisa e as necessidades de saúde da população.

Esse quadro perdurou até muito recentemente, quando uma parte importante da pesquisa em saúde em todo o mundo foi convidada a reorganizar-se para enfrentar o desafio das doenças emergentes ou reemergentes, cujo berço estava no Terceiro Mundo, mas que passaram a ameaçar crescentemente as populações do Hemisfério Norte. À mobilização proposta por organismos multilaterais, tendo à frente a Organização Mundial de Saúde, o Brasil reagiu com um conjunto de iniciativas que resultaram na realização da I Conferência Nacional de Ciência e Tecnologia em Saúde, em 1994. Pela primeira vez em nossa história, foi elaborada uma proposta explícita e abrangente de uma Política Nacional de Ciência e Tecnologia em Saúde.

Por várias razões, entre as quais a de ter sido realizada ao final de um período atípico (curto) de governo, a maioria das resoluções da Conferência não foi implementada. De qualquer modo, tratou-se de uma iniciativa de alta relevância e a maior parte do acervo de idéias que lá se desenvolveu permaneceu vivo até os dias de hoje. Em dezembro de 2000, a XI Conferência Nacional de Saúde deliberou pela ne- cessidade da realização da II Conferência Nacional de C\&T em Saúde, prevista para o primeiro semestre de 2004. Este gesto político mobilizou diversos atores envolvidos com o tema da pesquisa em saúde e várias organizações, entre as quais a Associação Brasileira de Pesquisa e Pós-graduação em Saúde Coletiva (Abrasco), produziram propostas de políticas nacionais orientadoras da pesquisa em saúde. As idéias que serão expostas a seguir foram, em sua maioria, debatidas no âmbito do Grupo de Trabalho em C\&T da Abrasco (Carlos Coimbra, Cecília Minayo, Célia Almeida, José da Rocha Carvalheiro, Madel Therezinha Luz, Maurício Lima Barreto, Moises Goldbaum, Reinaldo Guimarães (coordenador), Rita Barradas Barata.)

A política brasileira de C\&T privilegia a eleição de setores de atividade econômica como base de sua concepção e orientação. Esta ênfase, embora compreensível como direção geral, tem deixado de lado uma outra visão das políticas de C\&T, em setores que possuem uma enorme relevância no Brasil e nos quais a atividade de pesquisa deveria ocupar um lugar muito mais central do que ocupa hoje e do que jamais ocupou. Trata-se do olhar em direção aos setores de atividade social, em particular os de alimentação, saúde, habitação e educação.

Este olhar da política de C\&T em direção às políticas sociais possui também a virtude de operar um deslocamento na direção de um novo projeto nacional no qual possa ser mais valorizado o mercado interno e as necessidades da população brasileira. Por exemplo, no que se refere à alimentação, ao lado de aumentar a 
competitividade das commodities brasileiras de exportação (o que é, sem dúvida, importante), será essencial inaugurar linhas de apoio à pesquisa com vistas, por exemplo, a uma política de segurança alimentar. Uma nova PNCT\&I/S terá, portanto, o desafio de, ao mesmo tempo, fomentar o avanço do conhecimento científico no setor de saúde, orientar os vetores de desenvolvimento tecnológico e de inovação da indústria de equipamentos, medicamentos, imunizantes e outros insumos básicos à saúde, sempre sem perder de vista os mecanismos de apropriação societária dos resultados alcançados no conjunto de suas ações.

O aumento da ênfase na pesquisa dirigida às políticas sociais impõe também o desafio de mudar a escala de articulação entre os organismos gestores de cada uma delas no âmbito federal. Nesse terreno as experiências não têm sido bem-sucedidas e mudanças nos padrões de articulação são essenciais para diminuir o desperdício e aumentar a efetividade das ações de fomento. Nos quatro setores mencionados, uma forte sinergia entre os Ministérios da Ciência e Tecnologia, da Saúde, da Educação, da Agricultura e do Meio Ambiente será necessária.

\section{Fundamentos e diretrizes da política de pesquisa em saúde}

A desigualdade é o calcanhar-de-aquiles da civilização brasileira. Todo o progresso conquistado por gerações, em todos os campos em que isso foi observado, esbarra na marca infame muitas vezes crescente - da desigualdade. Não é diferente no campo da saúde. Os indicadores regionais e os referentes a diferentes grupos sociais em cada região demonstram a profunda discriminação social quanto à saúde, seja nos padrões de morbidade, de mortalidade, no acesso aos serviços, na qualidade do atendimento, na disponibilidade de infra-estrutura sanitária, enfim em qualquer aspecto da intervenção pública ou privada atinente à mesma. $\mathrm{O}$ compromisso de combater a marca da desigualdade no campo da saúde (aumentar os padrões de eqüidade do sistema de saúde) deve ser o primeiro fundamento básico da PNCT\&I/S e deve orientar todos os seus aspectos, todas as suas escolhas, em todos os momentos.

Em artigo recente, publicado no Bulletin of the World Health Organization, lê-se: Se o sistema de pesquisa em saúde de um país pode ser considerado o "cérebro" do seu sistema de saúde, então a ética constitui a sua "consciência". É imperativo que sistemas de saúde operem segundo as mais altas aspirações éticas e de justiça distributiva (Butha, 2002). Não resta dúvida de que as crescentes restrições observadas nos países centrais quanto a experimentos in anima nobile dentro de suas fronteiras têm estimulado a exportação de projetos de pesquisa, em particular de protocolos de ensaios clínicos e terapêuticos para serem executados em populações de países em desenvolvimento, em condições que seriam legalmente proibidas porque eticamente inaceitáveis no país de origem. O respeito estrito a padrões éticos na pesquisa deve ser o segundo fundamento básico da PNCT\&I/S.

Uma PNCT\&I/S voltada para as necessidades de saúde da população deveria ter como objetivo principal desenvolver e otimizar os processos de absorção de conhecimento científico e tecnológico pelas indústrias, pelos serviços de saúde e pela sociedade. O acatamento desta assertiva implica analisar o esforço nacional de C\&T em saúde como um componente setorial do sistema de inovação brasileiro. Por outro lado, essa perspectiva não deve sugerir uma visão reducionista ou utilitarista da política. Pelo contrário, reconhecendo a complexidade dos processos de produção de conhecimento científico e tecnológico neste setor, a PNCT\&I/S deve dar conta de todas as dimensões da cadeia do conhecimento envolvida na pesquisa em saúde. Em outras palavras, deve ser uma política extensiva. Este caráter extensivo por um lado e seu compromisso social, por outro, sugerem que a PNCT\&I/S necessita ser pensada, proposta e executada segundo um modelo de lógicas complementares. No plano de sua missão, segundo a lógica da Política Nacional de Saúde, à qual está subordinada, com suas prioridades e objetivos gerais vinculados ao atendimento das necessidades de saúde da população e à conquista de padrões mais elevados de eqüidade em saúde. No plano de seu exercício, segundo a lógica das práticas e métodos da pesquisa científica e do desenvolvimento tecnológico que são muitas vezes distintas das que governam a política de saúde.

Conceitualmente, no Brasil, não parece haver maiores dificuldades na delimitação do campo da pesquisa em saúde. Numa vertente de apreciação metodológica, o elemento central contido nesse conceito é que ele é fundado numa perspectiva de finalidade da ação da pesquisa: em outras palavras, numa perspectiva setorial. Entre outras coisas, a apropriação em- 
pírica do conceito de pesquisa em saúde baseado numa abordagem setorial sugere que ela deve ter um caráter abrangente, no sentido de incorporar uma grande variedade de atores, atuantes em outras áreas do conhecimento que não apenas as ciências da saúde e as ciências biológicas. O corolário imediato desse ponto de vista é que a PNCT\&I/S deve tratar de uma agenda que incorpore potencialmente todo o leque da pesquisa científica e tecnológica que tenha como finalidade, imediata ou mediata, contribuir para a melhoria do estado de saúde da população. Em outras palavras, que seja abrangente. Compromisso social, extensividade e abrangência, estas deverão ser as três características estruturais mais importantes de uma PNCT\&I/S brasileira.

\section{A pesquisa estratégica}

Vivemos uma época de intensas reformulações nos modelos explicativos do progresso técnico e, nesse contexto, um dos aspectos mais debatidos nos últimos anos tem sido o das relações entre a pesquisa científica e a inovação tecnológica. Estão sob tela de juízo faz bastante tempo as explicações lineares que trabalham com a perspectiva de que essas inovações são o ponto de chegada de um continuum cujo ponto de partida foi uma bancada de "pesquisa básica". Nessas novas aquisições conceituais deve ser ressaltada a pesquisa estratégica, que é relevante para uma PNCT\&I/S por várias razões. Entre outras, por ser o tipo de pesquisa capaz de mobilizar a maior parte dos pesquisadores ativos no país.

A ênfase na pesquisa estratégica, para os brasileiros, possui ainda um outro aspecto a ser ressaltado. Talvez não se trate apenas de priorizar um padrão original de prática de pesquisa, mas de recuperar uma tradição centenária em nosso país, posto que ela está na raiz histórica da pesquisa em saúde no Brasil, no Instituto Bacteriológico de São Paulo (com Adolfo Lutz), no Instituto de Manguinhos (com Oswaldo Cruz), no Instituto Butantã (com Vital Brasil) e no Instituto Biológico de São Paulo (com Artur Neiva e Rocha Lima). Essas instituições, desde o final do século 19 e até os anos 30 do século 20 , nada mais fizeram do que praticar a pesquisa estratégica de seu tempo, inspiradas no modelo de Pasteur. Um pouco mais tarde, podemos citar também o Instituto Evandro Chagas de Belém, tendo à frente o seu patrono. Nelas, cada uma a seu modo, fez-se uma pes- quisa experimental, muitas vezes de fronteira, que nunca teve dificuldade em manter seus compromissos com o atendimento às necessidades de saúde da população. Que foi capaz de amalgamar as aquisições desta pesquisa com a observação clínica e com a intervenção populacional de saúde pública, bem como tratou de transferir muitas de suas descobertas para o terreno da produção industrial (como no caso dos soros e vacinas). E que, finalmente, não deixou de formar recursos humanos qualificados e de disseminar seus achados através de revistas científicas de excelente nível, algumas existentes até hoje.

Naturalmente, nossa realidade atual é muito diferente da que existiu no tempo da fundação da pesquisa em saúde no Brasil. São novas instituições, a magnitude das tarefas e dos problemas é muito maior e os interesses nacionais e internacionais em jogo são gigantescos. No entanto, numa perspectiva heurística, a experiência histórica deve chamar nossa atenção para a possibilidade de uma redefinição dos padrões de pesquisa em saúde no país. Deve, além disso, sugerir uma direção para a mudança, na qual um olhar mais atento da comunidade científica e tecnológica às necessidades e às políticas de saúde não signifique um empobrecimento de sua capacidade de invenção ou uma perda de sua autonomia criativa.

\section{As ações atuais de fomento}

Uma análise das ações de fomento atuais no âmbito da pesquisa em saúde revela alguns aspectos importantes, a maior parte deles tributária da cinqüentenária tradição brasileira de apoio à pesquisa científica e tecnológica.

1) A qualidade e a transparência nas ações de fomento, em particular as realizadas pelas agências do MCT, pela Capes, bem como pela maioria das agências estaduais. Essas características decorrem da experiência brasileira com práticas de fomento em bases relativamente competitivas.

2) A baixa capacidade de indução, especialmente nas mesmas agências do MCT, na Capes e em algumas agências estaduais.

3) Especificamente no campo da pesquisa em saúde, a existência de uma tradição importante em termos de institutos de pesquisa federais e estaduais.

4) Um modelo de fomento descentralizado e plural, que também deve ser creditado à tradi- 
ção nacional de fomento e deve ser capitulado entre as suas qualidades. Historicamente, a pluralidade de agências tem sido um instrumento de proteção dos executores de pesquisa contra eventuais obscurecimentos no que se refere à qualidade e à transparência nas ações de fomento.

5) A ausência de mecanismos de coordenação adequados entre as múltiplas instâncias de fomento, em especial entre os dois atores principais, o MCT e o MS.

6) Uma baixa capacidade de articulação entre as ações de fomento científico-tecnológico e a política de saúde. Entre outras conseqüências, isto contribui para uma baixa capacidade de transferência de conhecimento novo para as indústrias, serviços de saúde e para a sociedade em geral.

7) Uma extensa e generalizada carência de atividades de pesquisa e desenvolvimento realizada nas empresas.

8) Finalmente, uma quantidade de recursos para o fomento bastante aquém das necessidades.

Essas características indicam o ponto de partida para uma PNCT\&I/S no que se refere à gestão das atividades de pesquisa. Por um lado, revelam a existência de um patrimônio institucional de execução e fomento muito importante. Por outro, apontam os principais empecilhos para um aproveitamento integral de suas capacidades, que são a falta de coordenação e a baixa capacidade de articulação apontadas acima.

Além do volume de recursos estar aquém das necessidades e, em grande parte, desvinculado de um critério racional de prioridades, a marca do modelo de gastos federais hoje em dia é a quase total desarticulação entre os financiadores principais. Com a exceção do $\mathrm{CNPq}$ e da Capes, que costumam entender-se, pelo menos quanto à distribuição de bolsas de mestrado e doutorado, em nada mais se percebe articulação. A falta de articulação entre o Ministério da Ciência e Tecnologia (MCT) e o Ministério da Saúde (MS) sustenta-se historicamente no seguinte: o MCT percebe no MS uma visão restritiva e imediatista da atividade de pesquisa (nos nossos termos, pouco extensiva e abrangente), além de não avalizar, de modo geral, as práticas de fomento do Ministério da Saúde. O ministério percebe na maioria das ações de fomento do MCT um quase total alheamento das necessidades de saúde da população e/ou das prioridades da política de saúde do país (nos nossos termos, ações com pouco compromisso social e divorciadas da busca de eqüida- de). O fato é que essa situação terminou por gerar um modelo de gestão política da pesquisa em saúde com características bifrontes, no qual o diálogo entre as suas duas cabeças não tem encontrado canais adequados para expressar-se. Naturalmente, para ser capaz de promover a articulação político-institucional proposta, uma nova PNCT\&I/S deve superar essa mais que falsa disjuntiva e buscar somar os aspectos positivos das duas tradições institucionais (Figura 1).

Portanto, ultrapassadas as heranças da tradição, cuja superação depende quase totalmente de determinação política, a nova PNCT\&I/S poderá então falar da necessidade de sustentar a pesquisa em saúde como um exercício de lógicas complementares. O mundo da pesquisa e o mundo do sistema de saúde não são integral ou perfeitamente correspondentes. Têm histórias, culturas e regras distintas, embora sejam capazes de conviver e convergir, nos marcos de objetivos corretamente estabelecidos. O sistema de saúde identificará os alvos e o sistema de pesquisa contribuirá para que sejam atendidos com efetividade. Em todos os ministérios envolvidos e também nos estados.

\section{A agenda de prioridades em pesquisa}

Finalmente, a PNCT\&I/S deveria adotar como diretriz a necessidade de aumentar a capacidade indutora do sistema de fomento científico e tecnológico. Se, como recomendou a I Conferência Nacional de Ciência e Tecnologia em Saúde (1994), concordamos que a pesquisa em saúde deve aproximar-se da Política Nacional de Saúde, então devemos propor o aumento de sua capacidade de induzir, com base numa escolha racional de prioridades. Para isso, o ponto mais importante a ser contemplado é a necessidade de construção de uma agenda de prioridades para a pesquisa em saúde. Uma das principais características históricas de nosso sistema de fomento à pesquisa é sua baixa seletividade, significando uma insuficiente capacidade de indução. E para que esta política mais indutiva possa ocorrer num ambiente de maior racionalidade, na perspectiva do interesse do país, é necessária a organização das necessidades de pesquisa segundo um padrão de prioridades. Se, como acreditamos, a pesquisa em saúde deve ser entendida como um exercício de lógicas complementares, a agenda de prioridades de pesquisa em saúde não será perfeita- 
Figura 1

Relações entre sistemas e políticas de saúde e de ciência e tecnologia. O modelo bifronte.

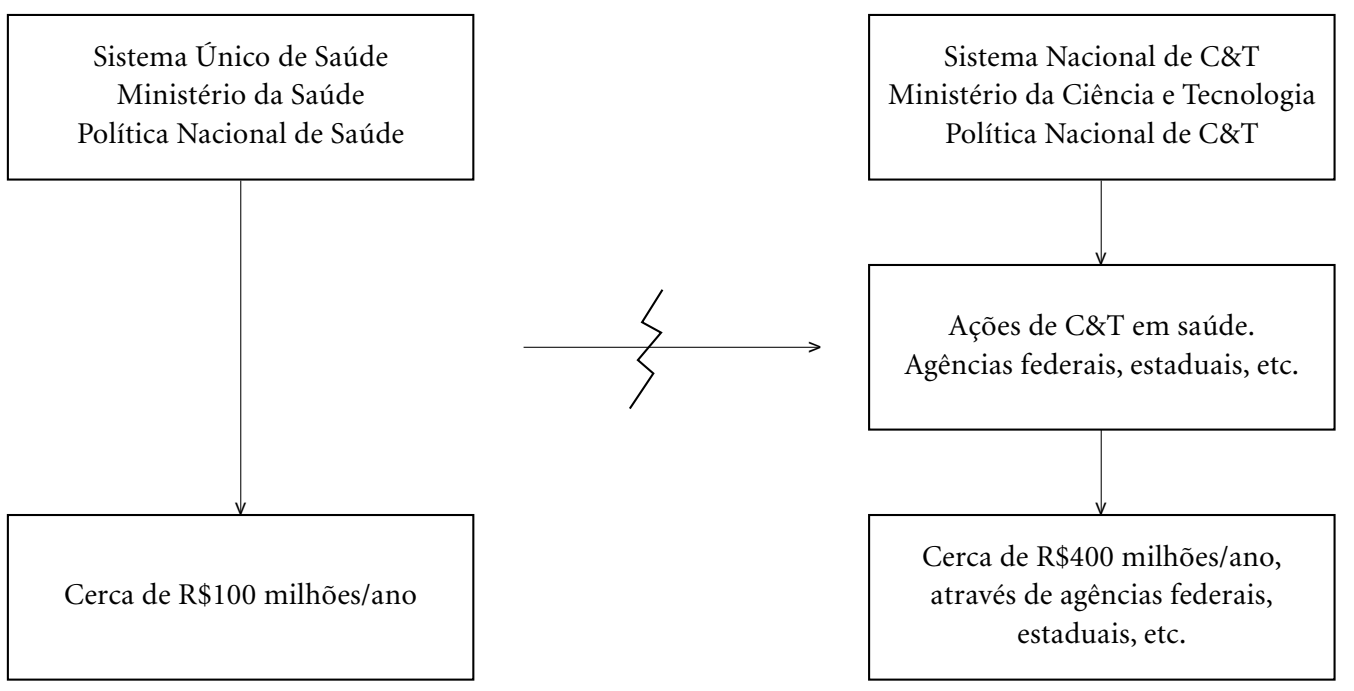

mente sobreposta à agenda de necessidades de saúde da população. Por um lado, o atendimento às necessidades de saúde nem sempre é uma variável dependente da pesquisa em saúde e, por outro, nem sempre há, no campo do saber e das práticas científicos e tecnológicos, conceitos, metodologia ou ferramentas adequados para que se possa produzir soluções através da pesquisa.

A agenda de prioridades não deve, também, ser subordinada ao olhar de curto prazo. Saúde e pesquisa em saúde são, ambas, urgentes. No entanto o tempo, os métodos e as estratégias dessas urgências são diferentes. A idéia da extensividade - incorporação na política de todas as etapas da cadeia do conhecimento - deve se expressar na agenda de prioridades. Nela estarão identificados os principais problemas de saúde cuja resolução depende da contribuição da pesquisa e estes problemas hão de requerer distintas abordagens de pesquisa. Haverá lugar para pesquisa operacional de curto prazo. Mas haverá também lugar para investigação fundamental bem como haverá lugar para a já mencionada pesquisa estratégica, que se desenvolve no ambiente da pesquisa fundamental, que lança mão de seu ferramental mas que, diferentemente dela, inclui desde a origem considerações de aplicação. E, por fim, o desenvolvimen- to de novos produtos e processos destinados ao sistema de saúde, realizado pelas empresas e pelos próprios serviços, também terá o seu lugar nessa agenda.

Numa palavra, esse deslocamento em direção à maior capacidade de indução, deve preservar e aperfeiçoar todas as características competitivas do fomento à pesquisa desenvolvidos nos últimos 50 anos no Brasil. Assim, as ações de fomento orientadas pela agenda de prioridades proposta no âmbito da PNCT\&I/S deveriam ter como forma canônica: a) a relevância como destino; b) o mérito como ponto de partida; e c) a competição como norma operacional básica.

Do conhecimento internacional acumulado na elaboração de agendas de prioridades e com o objetivo de inscrever a necessidade da elaboração de uma como estratégia básica da PNCT\&I/S, destacamos as seguintes características básicas. 1) Há mais de uma agenda de prioridades possível dependendo da orientação da política de pesquisa em saúde e uma boa agenda de prioridades deve estar a serviço dos princípios e das diretrizes daquela política. 2) A elaboração da proposta da agenda deve ser baseada no estado da arte do conhecimento científico e tecnológico disponível. Sua base técnica deve incorporar as melhores ferramentas e as evidências mais atualizadas. 3) A construção da 
agenda e, principalmente, sua implementação são processos de construção política. Pesquisa em saúde é um campo no qual atuam muitos atores distintos com experiências e linguagens distintas. Também com interesses e visões distintos da pesquisa e da saúde. Agregá-los a todos em torno ao conteúdo da agenda é a ação mais importante e esta ação objetiva, essencialmente, construir um consenso político em torno dela. O corolário desta proposição é que uma agenda de prioridades é uma ferramenta em permanente discussão e atualização.

A construção da Agenda é um processo técnico-político. Daí que durante todo o processo instâncias técnicas e instâncias políticas devem interferir. Com este objetivo, foi constituído um Comitê Técnico Assessor (CTA), composto de pesquisadores em biociências, epidemiologia e pesquisa clínica, além de gestores de saúde de larga experiência. Durante 2003 foram dados passos importantes no processo de construção da agenda, que culminaram na realização do seminário realizado em 6 e 7 de novembro. Seu objetivo foi a identificação de temas prioritários de pesquisa em saúde organizados em 12 subagendas e contou com a participação de cerca de 400 pessoas entre pesquisadores e gestores de saúde.

A etapa final do atual momento de construção da Agenda será sua apresentação ao plenário da II Conferência de Ciência, Tecnologia e Inovação em Saúde, a realizar-se no ano corrente, para debate e aprovação.

\section{Recursos para a pesquisa em saúde no Brasil}

São muito precárias as estimativas sobre gastos com pesquisa em saúde no Brasil, havendo neste momento uma iniciativa internacional destinada a avaliar o fluxo de recursos com esta finalidade do qual o Brasil participa, sob a coordenação do Ministério da Saúde. Conforme já foi mostrado, os números dos censos de 2000 e 2002 do Diretório dos Grupos de Pesquisa indicam que os números de grupos de pesquisa e de pesquisadores envolvidos com a pesquisa em saúde chegam a $30 \%$ do total. Tomando como referência o número de linhas de pesquisa, a porcentagem correspondente é $27 \%$. Por outro lado, levantamento preliminar do fluxo de recursos públicos para a pesquisa em saúde em 2001 atinge o volume de $\mathrm{R} \$ 500$ milhões, conforme os dados da tabela 3 .

Muito ou pouco dinheiro para o número de pesquisadores e de grupos envolvidos com pesquisa em saúde? Algum, mas certamente aquém das necessidades, principalmente se levarmos em conta o estado de crise em que se encontra a maioria dos hospitais universitários e de ensino, assunto que comentaremos mais adiante. Uma nova PNCT\&I/S deverá ter, entre suas ênfases, a de buscar novas fontes de recursos para a pesquisa em saúde.

Pode-se dizer que a pesquisa agropecuária brasileira se situa entre as mais articuladas com as políticas públicas de desenvolvimento seto-

\begin{tabular}{|c|c|c|c|c|c|c|}
\hline \multicolumn{7}{|c|}{$\begin{array}{l}\text { Tabela } 3 \\
\text { Desembolsos estimados em } 2001 \text { com atividades de pesquisa em saúde no setor público. } \\
\text { Principais fontes. }\end{array}$} \\
\hline Fonte & $\begin{array}{c}\text { Total } \\
\text { (mil R\$) }\end{array}$ & $\begin{array}{c}\text { Formação } \\
\text { de pessoal } \\
(\text { mil R\$) }\end{array}$ & $\begin{array}{l}\text { Apoio à } \\
\text { pesquisa } \\
(\text { mil R\$) }\end{array}$ & Total (\%) & $\begin{array}{l}\text { Formação } \\
\text { de pessoal } \\
\quad(\%)\end{array}$ & $\begin{array}{l}\text { Apoio à } \\
\text { pesquisa } \\
\quad(\%)\end{array}$ \\
\hline Ministério da Saúdel & $100.674,00$ & $35.617,00$ & $65.057,00$ & 20,3 & 13,2 & 28,6 \\
\hline Ministério da Ciência e Tecnologia & $156.917,00$ & $92.037,00$ & $64.880,00$ & 31,7 & 34,2 & 28,6 \\
\hline Finep ${ }^{2}$ & $26.577,00$ & & $26.577,00$ & 5,4 & & 11,7 \\
\hline $\mathrm{CNPq}^{3}$ & $130.340,00$ & $92.037,00$ & $38.303,00$ & 26,3 & 34,2 & 16,9 \\
\hline Ministério da Educação4 & $135.018,00$ & $112.790,00$ & $22.228,00$ & 27,2 & 42,0 & 9,8 \\
\hline Estado de São Paulo (Fapesp) 5 & $103.298,00$ & $28.418,00$ & $74.880,00$ & 20,8 & 10,6 & 33,0 \\
\hline Total & $495.907,00$ & $262.862,00$ & $227.045,00$ & 100,0 & 100,0 & 100,00 \\
\hline
\end{tabular}

1 Decit/SPS/MS. Investimentos em ações de C\&T em saúde no Ministério da Saúde em 2001.

2 Levantamento ad hoc realizado na carteira da Finep.

3 AEI/DAD/CNPq. Investimentos do CNPq em Estados e instituições em 2001.

4 Capes/MEC. Relatório da Capes para a Transição, 2002.

5 Revista Fapesp 79:20-23, setembro de 2002. 
rial. Embora detentora de uma histórica trajetória de sucessos, em particular no Estado de São Paulo, foi após a criação da Embrapa, em 1973, que esta articulação adquiriu maiores velocidade e intensidade. Faço essa digressão com vistas a comparar o financiamento público atual neste setor com o financiamento à pesquisa em saúde, mostrado nos quadros 1 e 2 .

Muito embora em termos absolutos o montante investido em pesquisa em saúde seja quase $60 \%$ maior do que o investido em pesquisa agropecuária, se ponderarmos esses valores pela massa crítica envolvida em cada um dos dois setores, chegaremos a uma situação distinta, apresentada no quadro 3.

$\mathrm{O}$ investimento anual per capita nos pesquisadores em saúde foi de $\mathrm{R} \$ 27.907,00$, contra $\mathrm{R} \$ 38.217,00$ destinados a cada pesquisador em agropecuária. Para que o aporte de recursos financeiros aos pesquisadores do setor saúde pudesse igualar-se ao dos pesquisadores do setor agropecuário, o desembolso em saúde em 2001 deveria ter sido de R 679 milhões ( R\$ 27.907,00 x 17.770). Em relação ao que foi efetivamente desembolsado, ficam faltando R\$ 183 milhões.

Pode ainda ser notado que a principal diferença no perfil do financiamento à pesquisa nos dois setores encontra-se exatamente na participação dos ministérios responsáveis pelos mesmos. Enquanto o Ministério da Saúde participa com $20 \%$ do total de investimentos na pesquisa em saúde, o Ministério da Agricultura, através da Embrapa, comparece com quase o dobro $(38,6 \%)$. Portanto, para gerir um montante de recursos adequado à importância da pesquisa em saúde no Brasil talvez seja necessário pensar uma estrutura vinculada ao Ministério da Saúde especializada em captar, fomentar, acompanhar e avaliar a atividade de pesquisa.

Há poucos anos foi lançada a idéia da criação de uma agência de fomento específica para a gestão da pesquisa em saúde. Essa idéia foi vitimada por um intenso conflito político-burocrático entre o MCT e o MS e acabou por ser retirada de pauta pelo próprio $\mathrm{MS}$, antes que pudesse ser melhor discutida. Consideramos que a proposta da agência deve voltar ao debate, posto que pode vir a tornar-se uma ferramenta essencial para a PNCT\&I/S. Esta agência teria a missão de coordenar a construção da agenda de prioridades de pesquisa em saúde, bem como de acompanhar sua operacionalização. Além disso, deveria também coordenar,

\section{Quadro 1}

Estimativa de desembolsos em 2001 com atividades de pesquisa em saúde no setor público. Brasil, principais fontes.

\begin{tabular}{lc}
\hline Fonte & Desembolsos (mil R\$) \\
\hline Ministério da Saúde ${ }^{1}$ & $100.674,00$ \\
Ministério da Ciência e Tecnologia & $156.917,00$ \\
$\quad$ Finep $^{2}$ & $26.577,00$ \\
CNPq $^{3}$ & $130.340,00$ \\
Ministério da Educação $^{4}$ & $135.018,00$ \\
Estado de São Paulo (Fapesp) & 5 \\
Total & $103.298,00$ \\
\hline
\end{tabular}

1 Decit/SPS/MS. Investimentos em ações de C\&T em saúde no MS em 2001.

2 Levantamento ad hoc realizado na carteira da Finep.

3 AEI/DAD/CNPq. Investimentos do CNPq em Estados e instituições em 2001.

4 Capes/MEC. Relatório da Capes para a Transição, 2002.

5 Revista Fapesp 79:20-23, setembro de 2002.

\section{Quadro 2}

Estimativa de desembolsos em 2001 com atividades de pesquisa agropecuária no setor público.

Brasil, principais fontes.

\begin{tabular}{|c|c|}
\hline Fonte & Desembolsos (mil R\$) \\
\hline Ministério da Agricultura 1 & $121.408,00$ \\
\hline Ministério da Ciência e Tecnologia & $77.923,00$ \\
\hline Finep ${ }^{2}$ & $10.000,00$ \\
\hline $\mathrm{CNPq}^{3}$ & $67.923,00$ \\
\hline Ministério da Educação 3 & $63.700,00$ \\
\hline Estado de São Paulo (Fapesp) ${ }^{3}$ & $61.649,00$ \\
\hline Total & $314.680,00$ \\
\hline \multicolumn{2}{|c|}{$\begin{array}{l}{ }^{1} \text { Relatório de Atividades 2001. Orçamento executado nos programas } \\
\text { de P\&D. }\end{array}$} \\
\hline \multicolumn{2}{|c|}{$\begin{array}{l}2 \text { Execução do Fundo de Agronegócios (R } \$ 8,1 \text { milhões) arredondado } \\
\text { para R\$ } 10 \text { milhões. }\end{array}$} \\
\hline \multicolumn{2}{|c|}{$\begin{array}{l}3 \text { Parcela do orçamento executada nos programas da grande área } \\
\text { de ciências agrárias (13\% do total do orçamento do CNPq). }\end{array}$} \\
\hline
\end{tabular}

em estrita articulação com as agências do MCT e com a Capes, a aplicação dos recursos para pesquisa em saúde, em particular os oriundos do MS. Numa palavra, deveria ser a principal guardiã de uma PNCT\&I/S renovada, como a que estamos propondo.

Em 2002, o Congresso Nacional aprovou a Lei do Fundo Verde-Amarelo, que reserva uma parte de seus recursos para a constituição de um Fundo específico para a saúde. As expectativas iniciais eram de que o valor do mesmo no ano de sua criação estaria em torno a R $\$ 90 \mathrm{mi}$ lhões. O valor comprometido em 2002 não che- 
Quadro 3

Número de linhas de pesquisa, pesquisadores e grupos associados aos setores de agricultura, pecuária, silvicultura e exploração florestal; e saúde humana. Brasil, 2002.

\begin{tabular}{lcrc}
\hline Setor & Grupos & Linhas & Pesquisadores \\
\hline Agricultura, pecuária, silvicultura, exploração florestal & 2.641 & 7.133 & 8.234 \\
Saúde humana & 4.914 & 13.688 & 17.770 \\
\hline
\end{tabular}

Pesquisador/ano em saúde humana: R 27.907,00.

Pesquisador/ano em agropecuária: R\$38.217,00.

gou a $5 \%$ da expectativa e para 2003 o valor comprometido deverá corresponder a menos da metade daquele originalmente estimado. Somado aos recursos já existentes, será um reforço, mas continuaremos aquém do necessário.

Mas talvez a maior renovação de fontes de recursos deva vir mesmo do Ministério da Saúde. Como vimos acima, o ministério desembolsa cerca de R $\$ 100$ milhões anuais com projetos fomentados por ele próprio e pelos institutos de pesquisa a eles vinculados. Ocorre que a seleção e contratação desses projetos não obedecem a qualquer agenda de prioridades do ministério como um todo, mas sim às prioridades de vários de seus componentes, por vezes contraditórias entre si. A primeira mudança importante seria, portanto, unificar as prioridades do Ministério da Saúde. Em segundo lugar, seria preciso estimular que as agências reguladoras subordinadas ao MS (Anvisa e ANS) venham participar das ações de fomento à pesquisa em saúde, aportando recursos financeiros. Em terceiro lugar, seria muito importante que a Secretaria de Assistência à Saúde, que é responsável pela execução do financiamento do SUS, pudesse aprofundar os esforços já em curso para que sua contribuição financeira à pesquisa nos hospitais de ensino fosse mais bem utilizada (comentaremos este ponto adiante). E, finalmente, será indispensável recolocar na agenda a proposta nascida no próprio MS há dois anos, que foi retirada de pauta pelo mesmo ministério e que trata da taxação das indústrias do tabaco e do álcool, com vistas à criação de um outro Fundo para financiar pesquisa em saúde. Pensamos que esta idéia deve retornar com uma ampliação conceitual, no sentido de fazer com que todos os setores industriais claramente produtores de "dívida sanitária" contribuam com um fundo para o fomento de pesquisa prioritária em saúde.

O Departamento de Ciência e Tecnologia do Ministério da Saúde teve, em 2003, uma do- tação orçamentária de cerca de R 13 milhões. Deve ser registrada a aprovação, pelo Congresso Nacional, de uma dotação correspondente de $\mathrm{R} \$ 67,8$ milhões para 2004. Cumpre ainda registrar que o Departamento de Assistência Farmacêutica, pertencente também à Secretaria de Ciência e Tecnologia, teve aprovada uma rubrica orçamentária específica para inovação tecnológica no setor farmacêutico no valor de $\mathrm{R} \$ 80$ milhões.

\section{Hospitais de ensino e avaliação tecnológica}

Nas últimas décadas, em escala mundial, tem sido observado um importante movimento da pesquisa em saúde em direção ao paciente hospitalar. Isso decorreu de vários fatores, entre os quais podem ser destacados: 1) a revolução na descoberta de moléculas bioativas e o conseqüente crescimento da necessidade de testá-las em populações humanas; 2) a igualmente importante revolução nos métodos diagnósticos, onde um dos espaços privilegiados de experimentação e desenvolvimento é também o hospital; 3) o envelhecimento populacional e o aumento correlato da incidência das enfermidades degenerativas, responsáveis pela internação de parte importante da população dos pacientes; 4) em conseqüência de tudo isso, o fortalecimento de medidas regulatórias destinadas a proteger os indivíduos que se submetem aos testes de novas drogas, métodos diagnósticos, etc. Estes e outros fatores terminaram por dar à pesquisa clínica uma nova importância no cenário geral da pesquisa em saúde e vieram fortalecer e consagrar o espaço hospitalar como um local privilegiado dessa pesquisa.

Na maioria dos países com atividade de pesquisa, os hospitais de ensino desenvolveram características de referência nessas atividades de pesquisa. A circunstância de estarem muitas 
vezes associados a universidades ou institutos de pesquisa e de abrigarem programas de graduação ou pós-graduação formadores de profissionais de saúde e de pesquisadores, fez com que neles os padrões de referência se instalassem com naturalidade. A tradição brasileira não é diferente. Historicamente, os hospitais de ensino brasileiros foram a vanguarda da pesquisa clínica e da avaliação de novos medicamentos e equipamentos, constituindo-se em instituições de referência.

O Sistema Único de Saúde (SUS) abriga hoje em dia mais de 6.000 hospitais, dos quais 154 $(2,6 \%)$ são reconhecidos pelos Ministérios da Saúde e da Educação como hospitais de ensino. Em 2001, estes foram responsáveis por $9 \%$ dos leitos, $12 \%$ das internações e $24 \%$ dos recursos do SUS. Responderam por cerca de $50 \%$ das cirurgias cardíacas, $70 \%$ dos transplantes e 50\% das neurocirurgias ocorridas no país. Os hospitais de ensino constituem um conjunto institucional muito heterogêneo, incluindo hospitais públicos federais, estaduais, municipais, hospitais privados filantrópicos e entidades públicas de direito privado. Heterogêneo, também, em termos da qualidade dos serviços que prestam.

Nos últimos anos, por vários motivos os hospitais de ensino brasileiros vêm passando por uma crise de graves proporções, em que um dos fulcros pode ser situado em dificuldades no seu financiamento. Em parte decorrentes da crise fiscal, em parte por opções de política macroeconômica e em parte pelo processo de desvalorização geral do serviço público verificado nos anos 90. Na realidade, crescentemente os hospitais de ensino vêm perdendo suas características históricas e talvez o componente que mais esteja sendo erodido na crise é o de uma de suas finalidades precípuas: as atividades de pesquisa. Se este breve diagnóstico é verdadeiro, então o que ocorre no Brasil neste terreno é o oposto da tendência internacional e, prosseguindo os problemas, provavelmente não teremos condições de desenvolver um dos componentes mais importantes da PNCT\&I/S. Em outras palavras, a pergunta a se fazer é: Será possível desenvolver a pesquisa clínica no Brasil, em níveis compatíveis com nossa tradição científica e na intensidade requerida pelos padrões internacionais sem que os hospitais de ensino ocupem um lugar central? A resposta é: muito provavelmente não.

Dentre os problemas bem estabelecidos no terreno da pesquisa em saúde atual, está o da assimetria entre a velocidade dos avanços (e também o tamanho dos custos) da pesquisa em bancada e a velocidade de apropriação do conhecimento produzido em benefício da população. Neste último componente, a velocidade é bem mais baixa e os custos são muito maiores. Este processo de apropriação pode ser denominado genericamente de Avaliação Tecnológica, incluindo o desenvolvimento de produtos e processos e, com grande intensidade, a realização de testagem clínica de novos medicamentos, equipamentos, normas operacionais, etc. O núcleo mais importante da atividade de pesquisa clínica nos hospitais de ensino vincula-se à avaliação tecnológica e é sobre ela que deveria recair a maioria dos esforços de uma política de recuperação da atividade de pesquisa nessas instituições.

Uma das expressões mais agudas da crise dos hospitais de ensino no Brasil é a decadência de sua infra-estrutura. A deterioração da infra-estrutura repercute sobre a prestação de serviços, sobre o ensino e, para o que mais nos interessa aqui, sobre a viabilidade da realização de pesquisa. Além disso, contribui para retirar do ambiente dos hospitais de ensino os profissionais, docentes ou não, capazes de realizar pesquisa e reproduzir a força de trabalho em pesquisa. Um dos aspectos mais contundentes na crise geral dos hospitais de ensino é a diminuição da dedicação temporal dos melhores profissionais ao hospital.

O modelo de financiamento atual do SUS para os hospitais de ensino agrega à remuneração-padrão pela prestação de serviços, um complemento denominado Fundo de Incentivo ao Desenvolvimento de Ensino e Pesquisa em Saúde (FIDEPS). Ele é fornecido como um complemento àquela remuneração e, com a crise do financiamento, os recursos do FIDEPS foram sendo crescentemente destinados ao custeio indiferenciado das atividades hospitalares, afastando-se de seus objetivos. Não será realista propor, hoje ou nos próximos anos, um retorno integral do FIDEPS à sua destinação original, pelo menos até que se recomponha a capacidade dos hospitais de reequilibrar suas contas na prestação de serviços.

Portanto, para a recuperação da infra-estrutura de pesquisa dos hospitais de ensino (mas também para apoiar o custeio das atividades de pesquisa neles realizadas) será necessário propor outro complemento específico, também no âmbito da política de financiamento do SUS, governado por um modelo de ges- 
tão que impeça o desvio de suas funções originais, conforme ocorreu com o FIDEPS. Para isso, este novo recurso deveria incorporar em sua gestão os padrões gerais de financiamento existentes nas agências de fomento à $\mathrm{C} \& \mathrm{~T}$, quais sejam: 1) solicitação de recursos mediante projetos detalhados; 2) disputa por recursos mediante processos competitivos; 3 ) acompanhamento e avaliação de resultados dos projetos financiados.

O Fundo de Infra-estrutura, gerido pelo MCT e operado pela Finep, destina-se ao fortalecimento da infra-estrutura de pesquisa em geral nas instituições públicas do país. Sua receita é composta por $20 \%$ do montante global do conjunto dos Fundos Setoriais. Começou a operar efetivamente em 2001 e em três editais lançados (até julho de 2002) aprovou projetos no valor de cerca de R\$260 milhões. Como parte do esforço de recompor a infra-estrutura de pesquisa dos hospitais de ensino, poderá ser negociado o lançamento de um edital anual ou bienal específico para esta finalidade, durante um certo número de anos. Amadurece, hoje em dia, a convicção de que os $20 \%$ dos recursos dos Fundos Setoriais destinados ao Fundo de Infra-estrutura são insuficientes para as finalidades deste último. A proposta da existência de editais específicos para a infra-estrutura de pesquisa em hospitais universitários está vinculada ao aumento daquele percentual.

$\mathrm{O}$ valor anual do FIDEPS repassado aos hospitais de ensino é de R 480 milhões. O valor do CT-Infra com um percentual, por exemplo, de $40 \%$ do montante dos Fundos pode ser estimado em cerca de R $\$ 350$ milhões/ano. Estimando-se um valor anual de R 50 milhões/ ano para os editais do novo incentivo do SUS/ FIDEPS e R\$ 30 milhões/ano para os editais do CT-Infra, teríamos um aporte de R\$ $130 \mathrm{mi}$ lhões/ano para a recuperação da infra-estrutura dos hospitais de ensino e para apoio de parte das atividades de custeio diretamente associadas à pesquisa, integralmente submetidos às boas práticas de avaliação de projetos. Esses montantes representariam menos de $10 \%$ do comprometimento anual do CT-Infra e pouco mais de $10 \%$ do valor atual do FIDEPS.

\section{O complexo industrial da saúde}

Por fim, é preciso mencionar que uma PNCT\&I/S num país como o Brasil deverá dar uma atenção especial ao desenvolvimento tecnológico e à inovação e, para tanto, deverá incorporar propostas e ações especificamente dirigidas ao Complexo Industrial da Saúde. Essa atenção decorre do fato de possuirmos uma estrutura industrial complexa e, em alguns setores, competitiva e, como já vimos, uma importante capacidade instalada de pesquisa acadêmica e em alguns institutos de pesquisa. Decorre também do fato de o país ter grande necessidade de utilização dos principais insumos industriais destinados à saúde - medicamentos, vacinas, soros, hemoderivados, kits diagnósticos e equipamentos - e de que um atendimento adequado dessas necessidades exige um máximo de capacitação tecnológica e, em vários aspectos, autonomia e auto-suficiência tecnológicas.

Cada um desses insumos à saúde apresenta características industriais e mercadológicas particulares, muito embora todos eles tenham, em comum, o fato de serem segmentos industriais de grande dinamismo e lucratividade em termos mundiais. Além disso, no que se refere aos medicamentos e às vacinas pode-se testemunhar uma verdadeira revolução tecnológica nas últimas décadas. No plano da estrutura industrial, essa revolução vem promovendo um movimento de concentração de capital e de tecnologia que resulta em imensos conglomerados multinacionais que competem/repartem o mercado mundial de medicamentos e também de vacinas. Este é o terreno sobre o qual teremos de construir nossa política tecnológica e de inovação em saúde e que, por si só, sugere o tamanho das dificuldades a serem enfrentadas.

Sem dúvida, o campo mais desafiador e difícil é o dos medicamentos e fármacos, no qual o processo de concentração e repartição do mercado mundial vai mais avançado e que, em conseqüência da equivocada abertura comercial indiscriminada observada no Brasil durante a década de 1990, nos fez recuar em relação ao que já havíamos conquistado em períodos anteriores. Nosso recuo nos fez perder terreno não apenas para os países líderes, mas também para outros países em desenvolvimento como a Índia e a China. A retomada de uma posição competitiva em relação a estes últimos países é uma tarefa básica da política tecnológica em saúde. O fortalecimento da empresa privada nacional e sua capacitação tecnológica é a rota mais importante para realizá-la. O grau de internacionalização do mercado de fármacos sugere que associações com empresas multinacionais em que estejam incluídos mecanismos de transferência tecnológica também sejam co- 
gitados. Finalmente, não deve deixar de ser mencionada a necessidade de ampliar, capacitar tecnologicamente e melhorar os modelos de gestão das poucas, muito embora importantes, instituições públicas produtoras de medicamentos.

Diferentemente do que se observa para os medicamentos, a produção de vacinas e soros é predominantemente pública, havendo, portanto, melhores condições para a construção de uma política tecnológica focada nas necessidades nacionais. Nesse terreno, talvez o desafio mais importante seja o de não deixar aumentar excessivamente a distância entre o Brasil e o conjunto de países produtores no que se refere à tecnologia de novas gerações de vacinas. Com ainda maior razão do que no caso dos medicamentos, as ações voltadas ao fortalecimento, capacitação tecnológica e melhoria da gestão dos produtores públicos são uma tarefa essencial.

Hemoderivados, kits e equipamentos possuem, cada um, suas especificidades de mercado e essas devem ser estabelecidas, examinadas e detalhadas de per si. O importante é que a construção do componente tecnológico da política de pesquisa em saúde seja realizada com base em evidências concretas da situação de mercado, das possibilidades tecnológicas autóctones e, principalmente, das necessidades nacionais. Para tanto, é de especial importância a realização de estudos prospectivos que orien- tem informadamente a construção da política, com a mobilização dos principais atores e tomadores de decisão públicos e privados envolvidos.

Uma das principais características de uma política de tecnologia e inovação em saúde é a sua flexibilidade. A definição dos alvos prioritários, os arranjos institucionais mais adequados para cada objetivo e os mecanismos de fomento a serem acionados devem obedecer à avaliação de cada situação específica. A definição dos alvos prioritários deve ser produto dos mencionados estudos de prospecção e deverão compor a agenda de prioridades de pesquisa em saúde. Os arranjos institucionais deverão, sempre que possível, privilegiar as empresas públicas e privadas, agentes decisivos no desenvolvimento tecnológico e, principalmente, na inovação. Quanto aos mecanismos de fomento, o leque deve ser aberto desde o apoio financeiro direto ao desenvolvimento de projetos nas empresas, passando pelo financiamento de arranjos onde se componham instituições de pesquisa e empresas até a encomenda de projetos específicos a institutos de pesquisa e universidades. Por outro lado, como instrumento de fomento, além do financiamento direto deve ser utilizada no limite do possível a capacidade de regulação do mercado por parte do Ministério da Saúde, através de suas compras de medicamentos, vacinas e outros insumos.

\section{Referências bibliográficas}

\author{
Buttha A 2002. Bulletin of the World Health Organization. \\ CNPq/PRE/AEI 2002. Diretório dos Grupos de Pesquisa \\ no Brasil. Censo 2002.
}

Artigo apresentado em 8/12/2003

Aprovado em 17/2/2004

Versão final apresentada em 2/3/2004 